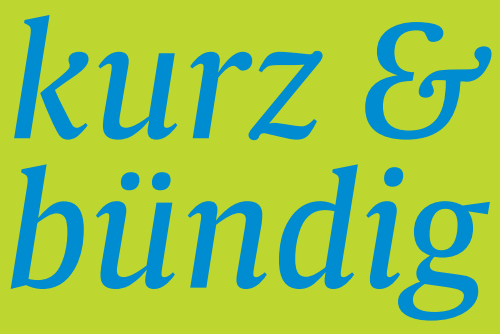

Beipackzettel führen oft zu Missverständnissen. Denn in europäischen Ländern fehlen Angaben darüber, welche Kausalität zwischen den Nebenwirkungen und der Medikamenteneinnahme besteht. Zudem gibt es keine Vergleichswerte darüber, wie häufig unerwünschte Symptome mit und ohne Einnahme auftreten.

Ik

PLOS ONE 2018; 9: e0203800

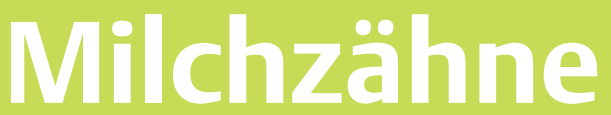

und deren Verlust sind die ersten körperlichen Veränderungen, die Kinder bewusst erleben. Ihre emotionale Reaktion darauf wird bestimmt durch Vorerfahrungen beim Zahnarzt, kulturelle Bedingungen und den Bildungsgrad der Eltern. Vier von fünf Kindern zeigen positive Gefühle wie Stolz. Ik

Int J Paediatr Dent 2018; doi:10.1111/ipd.12427

\section{Lebensmitte bestim-}

men durch ihre Inhaltsstoffe nicht nur den Geschmack, sie verändern auch unser Geschmacksempfinden. Zitronensäure zum Beispiel erhöht den Speichelfluss und dessen Natriumgehalt, sodass Salziges weniger salzig schmeckt. Ingwer hingegen sorgt für frischen Atem und einen guten Nachgeschmack.

J Agric Food Chem 2018; 29: 7740-7749

Beziehungen wirken sich auf das Körpergewicht aus. So leben Paare oftmals gesünder und länger als Singles, wiegen dafür aber im Durchschnitt mehr. Insbesondere in der Zeit nach dem Zusammenziehen steigt das Gewicht an, da man in Gesellschaft mehr isst. Health Psychol 2018; 10: 948-958

\section{V/US'K lindert Ängste und Schmerzen von}

Patienten, die sich einer Operation unterziehen müssen. Die positive Wirkung ist unabhängig von Geschlecht, Alter und Musikwahl. Ebenso gleichgültig sind der Zeitpunkt der Musikintervention (vor, während oder nach der Operation) und die Art der Narkose.

BrJ Surg 2018; 7: 773-783

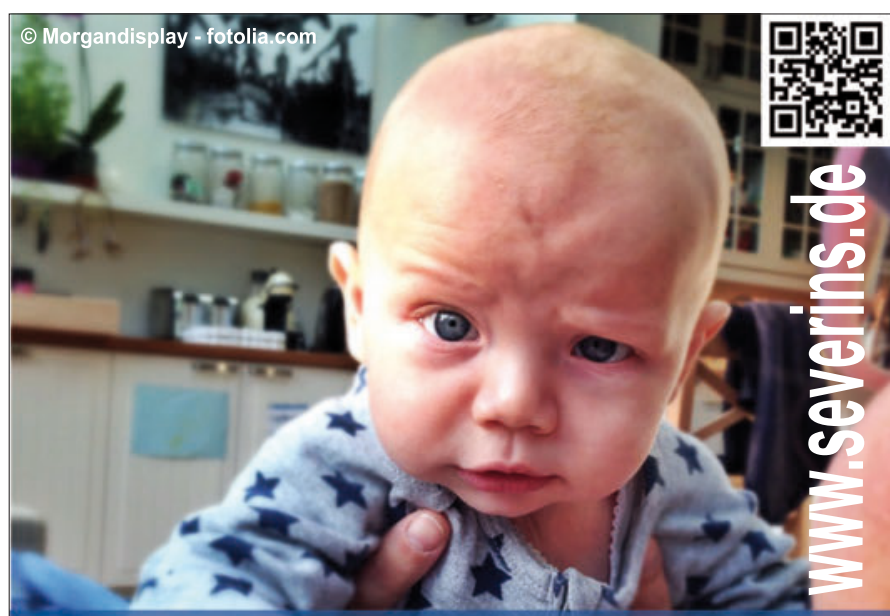

Wir entziehen uns nicht lhrem skeptischen Blick - wir wissen schließlich, was wir können...

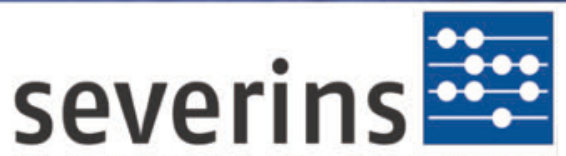

A B RECHNUNGEN. UND MEHR!
Severins GmbH

Am Lippeglacis 16 - 18

46483 Wesel

Tel.: 0281 - 16394 - 0

Fax: $0281-16394-10$
Besuchen Sie uns im Internet!

www.severins.de E-Mail: info@severins.de

\section{Thieme}

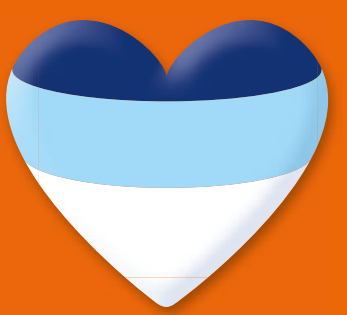

\section{Ergotherapeuten}

Auf unserer Facebook-Seite erwarten Dich viele tolle Beiträge: www.facebook.de/ thiemeliebtergotherapeuten

Besuche uns gleich. Wir freuen uns auf Dich!

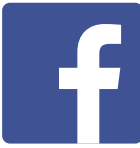

